\title{
Impact of Body Mass Index on Early Postoperative and Long-Term Outcome after Rectal Cancer Surgery
}

\author{
Björn Gebauera, Frank Meyer, $^{a, b}$ Henry Ptok $^{a, b}$ Ralf Steinert ${ }^{c}$ Ronny Otto ${ }^{a}$ \\ Hans Lippert ${ }^{a}$ Ingo Gastinger ${ }^{a}$ \\ a Institute of Quality Assurance in Operative Medicine, Otto-von-Guericke University at Magdeburg, Magdeburg, Germany; \\ ${ }^{b}$ Department of General, Abdominal, Vascular and Transplant Surgery, University Hospital, Magdeburg, Germany; \\ ${ }^{\mathrm{c}}$ Department of General and Abdominal Surgery, St Joseph Hospital, Salzkotten, Germany
}

\section{Keywords}

Rectal cancer · Body mass index, BMI .

Prospective multicenter observational study .

Research on clinical care

\section{Summary}

Background: The aim of this study was to investigate the impact of obesity and underweight onto early postoperative and long-term oncological outcome after surgery for rectal cancer. Methods: Data from 2008 until 2011 was gathered by a German prospective multicenter observational study. 62 items were reported by the physicians in charge, and a consecutive follow-up was performed if the patient had signed a consent form. Patients were subclassified into: underweight, normal weight, overweight, and obese - using the definitions of the World Health Organization. Results: In total, 9,920 patients were included, of whom $2.1 \%$ were underweight and $19.4 \%$ obese. The mean age was 68 years (range $21-99$ years). Postoperative morbidity (mean $38.0 \%$ ) was significantly increased in underweight and obese patients ( $p<0.001$ ). In-hospital mortality was $3.1 \%$ on average with no significant differences among patient groups ( $p$ $=0.176$ ). The 5 -year overall survival ranged between 36.9 and $61.3 \%$ and was worse in underweight and prolonged in overweight and obese patients compared to those with normal weight ( $p<0.001$ each). While the 5-year disease-free survival was increased in overweight and obese patients ( $p<0.05$ each), the 5 -year local recurrence rate showed no correlation ( $p>0.05$ each). Multi-

Both B.G. and F.M. are considered first authors with equal rights. variate analysis revealed that advanced age, higher ASA scoring, postoperative morbidity, and advanced tumor growth worsened the long-term survival independently. Conclusions: Underweight patients had a worse early and long-term outcome after rectal cancer surgery. Overweight and obesity were associated with a significantly better long-term survival.

(c) 2017 S. Karger GmbH, Freiburg

\section{Introduction}

Obesity is one of the global health challenges of the 21 st century. Its prevalence has risen during the last decades while a change is not expected [1]. Despite the associated comorbidities and negative influences on health, obesity is also a challenge in surgery. In general surgery, obese patients usually have a higher rate of postoperative complications, even when adjusted for confounders. Presumably, in-hospital mortality is not influenced [2,3]. A relatively common malignant disease that requires surgical treatment is rectal cancer. For example, rectal cancer is expected to cause almost 40,000 cases in the USA in 2017 [4]. Concerning the cancer-specific surgical treatment, postoperative complications are more common in obese patients $[5,6]$. In contrast, there is some indication of an 'obesity paradox' in general surgery for overweight and obese patients [2]. It describes the fact that obesity is related to decreased mortality or increased survival after surgery. The respective literature on rectal cancer resections does not show agreement as to its validity, though $[7,8]$.

Besides obesity, underweight including tumor-induced cachexia is also a remarkable issue when it comes to oncological surgery.

\section{KARGER}

() 2017 S. Karger GmbH, Freiburg
Prof. Dr. Frank Meyer

Department of General, Abdominal, Vascular, and Transplant Surgery University Hospital

Leipziger Straße 44, 39120 Magdeburg, Germany

frank.meyer@med.ovgu.de 
Table 1. Patients' characteristics of the consecutive multicenter patient cohort depending on BMI $\left(\mathrm{kg} / \mathrm{m}^{2}\right)$ in rectal cancer surgery subdivided according to ASA classification and various tumor stages

\begin{tabular}{|c|c|c|c|c|c|c|c|c|c|c|c|}
\hline & \multirow[t]{3}{*}{ Valid, $\mathrm{n}$} & \multirow[t]{3}{*}{ Mean, \% } & \multicolumn{8}{|c|}{$\mathrm{BMI}, \mathrm{kg} / \mathrm{m}^{2}$} & \multirow[t]{3}{*}{ p-value } \\
\hline & & & \multicolumn{2}{|c|}{$<18.5$} & \multicolumn{2}{|c|}{$18.5-24.9$} & \multicolumn{2}{|l|}{$\geq 25.0$} & \multicolumn{2}{|c|}{$\geq 30.0$} & \\
\hline & & & $\mathrm{n}$ & $\%$ & $\mathrm{n}$ & $\%$ & $\mathrm{n}$ & $\%$ & $\mathrm{n}$ & $\%$ & \\
\hline \multicolumn{12}{|c|}{ Physical status - ASA classification } \\
\hline ASA I & \multirow{4}{*}{9,893} & 7.7 & 18 & 8.6 & 370 & 9.8 & 329 & 8.2 & 43 & 2.2 & \multirow{4}{*}{$<0.001$} \\
\hline ASA II & & 50.8 & 64 & 30.5 & 1,910 & 50.8 & 2,124 & 53.0 & 929 & 48.4 & \\
\hline ASA III & & 39.0 & 109 & 51.9 & 1,375 & 36.6 & 1,468 & 36.7 & 903 & 47.0 & \\
\hline ASA IV & & 2.5 & 19 & 9.0 & 103 & 2.7 & 83 & 2.1 & 46 & 2.4 & \\
\hline \multicolumn{12}{|c|}{ Tumor stage - UICC classification } \\
\hline UICC 1 & \multirow{4}{*}{9,017} & 29.6 & 38 & 20.2 & 900 & 26.3 & 1,151 & 31.4 & 584 & 33.4 & \multirow{4}{*}{$<0.001$} \\
\hline UICC 2 & & 24.1 & 58 & 30.9 & 856 & 25.0 & 866 & 23.7 & 397 & 22.7 & \\
\hline UICC 3 & & 28.1 & 43 & 22.9 & 945 & 27.6 & 1,044 & 28.5 & 502 & 28.7 & \\
\hline UICC 4 & & 18.1 & 49 & 26.1 & 720 & 21.0 & 599 & 16.4 & 265 & 15.2 & \\
\hline
\end{tabular}

Mortality and in-hospital rates are higher in underweight patients than in patients with a body mass index $(\mathrm{BMI})>18.5 \mathrm{~kg} / \mathrm{m}^{2}[3,5]$. The influence on the long-term outcome is not concordant so far $[2,8]$. The same applies to the postoperative complication rate [2, $3,5]$. Furthermore, different definitions for underweight and exclusion of certain surgical procedures can lead to the difficulty that a general conclusion cannot be derived.

The aim of this study was to investigate whether early postoperative and oncosurgical long-term outcomes are influenced by the patient's BMI to reflect daily oncosurgical care for primary rectal cancer in Germany and to provide more evidence to the inconsistent data from the literature.

\section{Methods}

The prospective multicenter observational study 'rectal cancer (primary tumor) - elective surgery' was used for gathering data. This study in the field of clinical care research was developed and conducted by the Institute of Quality Assurance in Operative Medicine at the Otto-von-Guericke University of Magdeburg, Germany. The study was initiated on January 1, 2005. Data from 2008 until 2011 was prospectively documented and retrospectively analyzed. In total, 10,625 patients were reported during this time period. Inclusion criteria were patients undergoing elective surgical treatment of a histologically secured primary rectal cancer at a participating hospital in Germany. The patient had to be at least 18 years old. No exclusion was made concerning participating hospitals. A standardized registration form of 68 items was completed by the responsible surgeons in the various surgical departments/hospitals of each level of care and was submitted via email or online. Every patient had to sign a consent form in order to take part in this study and the consecutive follow-up. This procedure was repeated every year and was reported by the physicians at the outpatient clinics.

The patients were subdivided into four groups according to the definition of the World Health Organization (WHO) for the BMI [9], without further severity discrimination of obesity, i.e. underweight $\left(\mathrm{BMI}<18.5 \mathrm{~kg} / \mathrm{m}^{2}\right)$; normal weight (BMI $18.5-24.9 \mathrm{~kg} / \mathrm{m}^{2}$ ); overweight (BMI $\geq 25.0 \mathrm{~kg} / \mathrm{m}^{2}$ ); obesity (BMI $\geq$ $\left.30.0 \mathrm{~kg} / \mathrm{m}^{2}\right)$.

A detailed description of the used method has already been published [10]. In total, 62 items were eligible for analysis. In brief, preoperative parameters included diagnosis at admission, age, BMI, tumor localization, risk factors such as cardiac or pulmonary risks as well as physical status classified by the American Society of Anesthesiologists (including ASA I-IV), and performed diagnos- tics including preoperative histological findings and presence of distant metastasis, bowel preparation, neoadjuvant therapies, use of antibiotics, and thromboembolic prophylaxis. The surgeon's experience, duration of operation and surgical procedure including radical, limited and local procedures, type of anastomosis, resection of multiple organs, and complications as well as clinical Mercury classification and $\mathrm{R}$ status were considered perioperative parameters. Postoperatively, general and surgery-related morbidity as well as in-hospital mortality, admission to another clinic, adjuvant or palliative therapies, and duration of hospital stay were analyzed. Furthermore, a detailed histopathological analysis was conducted, including type and grading of tumor, tumor stage according to TNM classification including $\mathrm{L}$ and $\mathrm{V}$ status, and tumor stage classified by Union International Contre le Cancer (UICC) as well as size, invasion of other organs, and pathological Mercury classification as well as coning. Six items of the original protocol for documenting rectal cancer patients at the Institute for Quality Assurance were identified as not being valid for analysis.

Primary endpoints were postoperative morbidity including general and surgery-related complications, in-hospital mortality, and long-term survival. This included 5-year overall survival (5-year OS), 5-year disease-free survival (5-year DFS), and 5-year local recurrence rate. Endpoints for disease-free survival were appearance of metastasis, local recurrence, second malignancy, and patient's death. Only patients with R0 resections and tumors staged as UICC IIII were included.

Statistics

Gathered data was managed by means of a study-specific database, which included validation criteria. SPSS ${ }^{\circledR}$ (version 21 ; IBM $^{\circledR}$; Chicago, IL, USA) was used for statistical analysis. Used statistical models were Kruskal-Wallis test for continuous variables, chi-square test for cross tables, and Kaplan-Meier estimator with log-rank test for long-term data. Furthermore, multivariate analysis was performed using logistic regression for postoperative morbidity and inhospital mortality, and Cox regression for 5-year OS and 5-year DFS. All significantly differing items among various BMI-related patient groups were included in those analyses. Due to the little amount of reported cases, a Cox regression concerning the local recurrence rate was not possible. For all statistical tests, a p-value of $<0.05$ was considered significant. The tables are showing the last step of analysis, whereas items not listed were discarded during the previous step. Odds ratio (OR) or hazard ratio (HR) are given including the $95 \%$ confidence interval (CI).

\section{Final Remark}

All patients gave their written informed consent prior to surgical intervention.

The study was performed in accordance with the Helsinki guidelines for biomedical research from 1964 and their further updates, regulations set by the local ethics committee, as well as the basics of 'good clinical practice'. 
Table 2. Postoperative complications of the consecutive multicenter patient cohort depending on BMI $\left(\mathrm{kg} / \mathrm{m}^{2}\right)$ in rectal cancer surgery subdivided according to morbidity, general and specific postoperative complications

\begin{tabular}{|c|c|c|c|c|c|c|c|c|c|c|c|}
\hline & \multirow[t]{3}{*}{ Valid, n } & \multirow[t]{3}{*}{ Mean, \% } & \multicolumn{8}{|c|}{ BMI, kg/m² } & \multirow[t]{3}{*}{ p-value } \\
\hline & & & \multicolumn{2}{|c|}{$<18.5$} & \multicolumn{2}{|c|}{$18.5-24.9$} & \multicolumn{2}{|l|}{$\geq 25.0$} & \multicolumn{2}{|c|}{$\geq 30.0$} & \\
\hline & & & $\mathrm{n}$ & $\%$ & $\mathrm{n}$ & $\%$ & $\mathrm{n}$ & $\%$ & $\mathrm{n}$ & $\%$ & \\
\hline Morbidity in total & 9,920 & 38.0 & 92 & 43.4 & 1,379 & 36.6 & 1,477 & 36.8 & 826 & 42.9 & $<0.001$ \\
\hline \multicolumn{12}{|c|}{ General postoperative complications } \\
\hline At least one & 9,920 & 18.1 & 54 & 25.5 & 684 & 18.1 & 691 & 17.2 & 364 & 18.9 & 0.013 \\
\hline Urinary tract infection & 9,920 & 5.2 & 14 & 6.6 & 200 & 5.3 & 201 & 5.0 & 102 & 5.3 & 0.737 \\
\hline Pulmonary & 9,920 & 2.7 & 20 & 9.4 & 106 & 2.8 & 96 & 2.4 & 49 & 2.5 & $<0.001$ \\
\hline Pneumonia & 9,920 & 3.7 & 15 & 7.1 & 151 & 4.0 & 134 & 3.3 & 66 & 3.4 & 0.022 \\
\hline Cardiac & 9,920 & 3.6 & 8 & 3.8 & 140 & 3.7 & 135 & 3.4 & 78 & 4.1 & 0.596 \\
\hline Thrombosis & 9,920 & 0.4 & 0 & 0.0 & 12 & 0.3 & 15 & 0.4 & 16 & 0.8 & 0.024 \\
\hline Pulmonary embolism & 9,920 & 0.4 & 2 & 0.9 & 16 & 0.4 & 12 & 0.3 & 11 & 0.6 & 0.272 \\
\hline Renal & 9,920 & 2.2 & 4 & 1.9 & 68 & 1.8 & 94 & 2.3 & 48 & 2.5 & 0.262 \\
\hline Neurological/Psychiatric & 9,920 & 2.4 & 6 & 2.8 & 91 & 2.4 & 97 & 2.4 & 47 & 2.4 & 0.985 \\
\hline Multi-organ failure & 9,920 & 1.3 & 2 & 0.9 & 49 & 1.3 & 47 & 1.2 & 35 & 1.8 & 0.212 \\
\hline 'Others' & 9,920 & 3.1 & 10 & 4.7 & 122 & 3.2 & 116 & 2.9 & 55 & 2.9 & 0.389 \\
\hline \multicolumn{12}{|c|}{ Surgery-related postoperative complications } \\
\hline At least one & 9,920 & 29.0 & 60 & 28.3 & 1,009 & 26.8 & 1,152 & 28.7 & 652 & 33.9 & $<0.001$ \\
\hline Bladder emptying disorder & 9,920 & 2.9 & 7 & 3.3 & 97 & 2.6 & 125 & 3.1 & 56 & 2.9 & 0.532 \\
\hline Bleeding requiring surgery & 9,920 & 1.3 & 1 & 0.5 & 53 & 1.4 & 46 & 1.1 & 26 & 1.4 & 0.527 \\
\hline Sepsis & 9,920 & 1.6 & 4 & 1.9 & 55 & 1.5 & 59 & 1.5 & 45 & 2.3 & 0.061 \\
\hline Aseptic wound healing & 9,920 & 3.0 & 5 & 2.4 & 86 & 2.3 & 130 & 3.2 & 77 & 4.0 & 0.002 \\
\hline $\begin{array}{l}\text { Anastomotic insufficiency } \\
\text { requiring surgery }\end{array}$ & 9,920 & 4.2 & 9 & 4.2 & 154 & 4.1 & 170 & 4.2 & 85 & 4.4 & 0.949 \\
\hline $\begin{array}{l}\text { Anastomotic insufficiency not } \\
\text { requiring surgery }\end{array}$ & 9,920 & 3.4 & 5 & 2.4 & 116 & 3.1 & 143 & 3.6 & 74 & 3.8 & 0.337 \\
\hline Ileus & 9,920 & 1.9 & 3 & 1.4 & 76 & 2.0 & 82 & 2.0 & 26 & 1.4 & 0.250 \\
\hline Atony for more than 3 days & 9,920 & 3.5 & 5 & 2.4 & 126 & 3.3 & 136 & 3.4 & 83 & 4.3 & 0.175 \\
\hline Wound infection laparotomy & 9,920 & 4.4 & 12 & 5.7 & 122 & 3.2 & 161 & 4.0 & 144 & 7.5 & $<0.001$ \\
\hline Abscess & 9,920 & 1.7 & 6 & 2.8 & 60 & 1.6 & 64 & 1.6 & 42 & 2.2 & 0.197 \\
\hline Enteroatmospheric fistula & 9,920 & 0.4 & 1 & 0.5 & 13 & 0.3 & 15 & 0.4 & 9 & 0.5 & 0.906 \\
\hline Wound infection sacral cavity & 9,920 & 3.7 & 4 & 1.9 & 150 & 4.0 & 129 & 3.2 & 80 & 4.2 & 0.086 \\
\hline Peritonitis & 9,920 & 1.1 & 3 & 1.4 & 35 & 0.9 & 42 & 1.0 & 26 & 1.4 & 0.491 \\
\hline Colostomy complication & 9,920 & 1.0 & 2 & 0.9 & 42 & 1.1 & 29 & 0.7 & 30 & 1.6 & 0.027 \\
\hline Multi-organ failure & 9,920 & 0.7 & 1 & 0.5 & 25 & 0.7 & 22 & 0.5 & 26 & 1.4 & 0.007 \\
\hline Wound rupture of laparotomy & 9,920 & 1.8 & 4 & 1.9 & 59 & 1.6 & 60 & 1.5 & 57 & 3.0 & $<0.001$ \\
\hline 'Others' & 9,920 & 3.6 & 11 & 5.2 & 128 & 3.4 & 132 & 3.3 & 84 & 4.4 & 0.094 \\
\hline
\end{tabular}

\section{Results}

In total, 9,920 patient records were eligible for analysis (acquisition rate: $93.4 \%$ ). These were reported by 183 hospitals (range: 1-187 patients per hospital). The male-to-female ratio was 1.61 to 1. In total, $2.1 \%$ of the patients were underweight $(n=212), 38.0 \%$ normal weight $(\mathrm{n}=3,770), 40.5 \%$ overweight $(\mathrm{n}=4,014)$, and $19.4 \%$ obese $(n=1,924)$

The mean age was 68 years (range: $21-99$ years). Obese patients (Ø: 66.83 years) were significantly younger than underweight ( weight ( $\varnothing: 68.17$ years) cases $(\mathrm{p}<0.001)$. Concerning the preoperative physical status as classified by the ASA scoring (I-IV), underweight and obese patients were more critically classified than others ( $p<0.001)$. ASA III was more often found in underweight patients $(51.9 \%)$ and obese patients $(47.0 \%)$ than in normal-weight (36.6\%) and overweight (36.7\%) subjects. Furthermore, underweight patients showed advanced and overweight as well as obese patients had significantly less advanced tumor stages according to UICC than normal-weight individuals $(\mathrm{p}<0.001)$. UICC-IV carcinoma patients were found in $26.1 \%$ of all underweight patients compared to $21.0 \%$ in normal-weight, $16.4 \%$ in overweight and $15.2 \%$ in obese ones. UICC-I tumors appeared in $33.4 \%$ obese and $31.4 \%$ overweight patients compared to $26.3 \%$ in normal-weight and $20.2 \%$ in underweight ones. The patients' characteristics are shown in table 1. 
Table 3. Surgical quality measures diagnosed by pathologist depending on BMI $\left(\mathrm{kg} / \mathrm{m}^{2}\right)$

\begin{tabular}{|c|c|c|c|c|c|c|c|c|c|c|c|}
\hline & \multirow[t]{3}{*}{ Valid, n } & \multirow{3}{*}{$\begin{array}{l}\text { Mean, } \\
\%\end{array}$} & \multicolumn{8}{|c|}{ BMI, $\mathrm{kg} / \mathrm{m}^{2}$} & \multirow[t]{3}{*}{ p-value } \\
\hline & & & \multicolumn{2}{|c|}{$<18.5$} & \multicolumn{2}{|c|}{$18.5-24.9$} & \multicolumn{2}{|l|}{$\geq 25.0$} & \multicolumn{2}{|l|}{$\geq 30.0$} & \\
\hline & & & $\mathrm{n}$ & $\%$ & $\mathrm{n}$ & $\%$ & $\mathrm{n}$ & $\%$ & $\mathrm{n}$ & $\%$ & \\
\hline \multicolumn{12}{|l|}{ Tumor positive margin } \\
\hline Oral & 9,370 & 0.1 & 0 & 0.0 & 7 & 0.2 & 5 & 0.1 & 2 & 0.1 & 0.764 \\
\hline Aboral & 9,397 & 0.8 & 6 & 3.4 & 31 & 0.9 & 18 & 0.5 & 16 & 0.9 & $<0.001$ \\
\hline Radial & 8,990 & 3.5 & 10 & 5.9 & 140 & 4.2 & 114 & 3.1 & 48 & 2.7 & 0.006 \\
\hline Adjacent organ & 1,970 & 6.8 & 9 & 13.6 & 57 & 6.9 & 44 & 6.2 & 23 & 6.4 & 0.142 \\
\hline Distant metastasis & 753 & 21.4 & 4 & 19.0 & 63 & 19.9 & 66 & 23.6 & 28 & 20.7 & 0.722 \\
\hline Coning, yes & 8,462 & 4.6 & 11 & 6.9 & 161 & 5.1 & 143 & 4.1 & 73 & 4.4 & 0.132 \\
\hline \multicolumn{12}{|l|}{ Mercury } \\
\hline Grade 1 & & 84.3 & 122 & 79.2 & 2,533 & 83.0 & 2,860 & 85.5 & 1,360 & 84.8 & \\
\hline Grade 2 & 8,152 & 12.4 & 24 & 15.6 & 407 & 13.3 & 387 & 11.6 & 191 & 11.9 & 0.075 \\
\hline Grade 3 & & 3.3 & 8 & 5.2 & 110 & 3.6 & 97 & 2.9 & 53 & 3.3 & \\
\hline
\end{tabular}

Table 4. Type of discharge or death after hospital stay for rectal cancer surgery and further planned treatment depending on BMI $\left(\mathrm{kg} / \mathrm{m}^{2}\right)$

\begin{tabular}{|c|c|c|c|c|c|c|c|c|c|c|c|}
\hline & \multirow[t]{3}{*}{ Valid, n } & \multirow{3}{*}{$\begin{array}{l}\text { Mean, } \\
\%\end{array}$} & \multicolumn{8}{|c|}{ BMI, kg/m² } & \multirow[t]{3}{*}{ p-value } \\
\hline & & & \multicolumn{2}{|c|}{$<18.5$} & \multicolumn{2}{|c|}{$18.5-24.9$} & \multicolumn{2}{|l|}{$\geq 25.0$} & \multicolumn{2}{|l|}{$\geq 30.0$} & \\
\hline & & & $\mathrm{n}$ & $\%$ & $\mathrm{n}$ & $\%$ & $\mathrm{n}$ & $\%$ & $\mathrm{n}$ & $\%$ & \\
\hline Discharge & 9,918 & 93.9 & 184 & 86.8 & 3,521 & 93.4 & 3,796 & 94.6 & 1,813 & 94.2 & $<0.001$ \\
\hline Transfer & 9,918 & 3.0 & 18 & 8.5 & 118 & 3.1 & 108 & 2.7 & 53 & 2.8 & $<0.001$ \\
\hline Death & 9,918 & 3.1 & 10 & 4.7 & 129 & 3.4 & 110 & 2.7 & 58 & 3.0 & 0.176 \\
\hline \multicolumn{12}{|c|}{ Planned further treatment } \\
\hline Adjuvant RCTx & 9,920 & 13.2 & 22 & 10.4 & 464 & 12.3 & 564 & 14.1 & 264 & 13.7 & 0.070 \\
\hline Adjuvant CTx & 9,920 & 29.8 & 49 & 23.1 & 1,108 & 29.4 & 1,201 & 29.9 & 597 & 31.0 & 0.100 \\
\hline Palliative CTx & 9,920 & 12.9 & 38 & 17.9 & 551 & 14.6 & 470 & 11.7 & 216 & 11.2 & $<0.001$ \\
\hline Palliative RTx & 9,920 & 2.2 & 7 & 3.3 & 104 & 2.8 & 64 & 1.6 & 41 & 2.1 & 0.003 \\
\hline
\end{tabular}

$\mathrm{CTx}=$ Chemotherapy; $\mathrm{RTx}=$ radiotherapy $\mathrm{RCTx}=$ radiochemotherapy.
The postoperative morbidity was $38.0 \%$. If the patient was underweight $(43.4 \%)$ or obese $(42.9 \%)$, this rate was significantly higher than in normal-weight $(36.6 \%)$ or overweight $(36.8 \%)$ patients $(\mathrm{p}<0.001)$.

General postoperative complications occurred in $25.5 \%$ of underweight, $18.1 \%$ of normal-weight, $17.2 \%$ of overweight and $18.9 \%$ of obese patients $(\mathrm{p}=0.013)$. Underweight patients showed significantly more pulmonary complications $(\mathrm{p}<0.001)$ and pneumonia $(\mathrm{p}=0.022)$ than patients with a BMI of at least $18.5 \mathrm{~kg} / \mathrm{m}^{2}$. In contrast, obese patients developed significantly more thrombosis $(\mathrm{p}=0.024)$ than other cases. Other complications were not significantly associated with the patients' BMI, including urinary tract infection ( $p=0.737$ ) with a rate of $5.2 \%$ of all cases, cardiac complications $(\mathrm{p}=0.596)$ with $3.6 \%$, pulmonary embolism $(\mathrm{p}=0.272)$ with $0.4 \%$, renal complications $(\mathrm{p}=0.262)$ with $2.2 \%$, neurological or psychiatric complications ( $\mathrm{p}=0.985$ ) with $2.4 \%$, multi-organ failure ( $\mathrm{p}=0.212)$ with $1.3 \%$, and 'others' $(\mathrm{p}=0.389)$ with $3.1 \%$.

Surgery-related complications were significantly more often found in obese patients (33.9\%) than in underweight (28.3\%), normal-weight (26.8\%) and overweight (28.7\%) subjects who showed comparable rates $(\mathrm{p}<0.001)$. These complications included wound infection ( $p=0.002 ; 4.0 \%$ of all obese patients), infection of the laparotomy wound ( $\mathrm{p}<0.001 ; 7.5 \%$ of the obese patients), complications at the colostoma site ( $\mathrm{p}=0.027 ; 1.6 \%$ of the obese individuals), and wound rupture of laparotomy ( $<<0.001 ; 3.0 \%)$. In this category, multi-organ failure occurred significantly more often in obese patients ( $p=0.007$ ) but was scarcely reported than in the category of general postoperative complications. All other surgery-related complications showed no significant differences, including anastomotic insufficiency. Insufficiency occurred in $4.2 \%$ of all cases requiring surgery $(\mathrm{p}=0.949)$ and in $3.4 \%$ without required surgery $(\mathrm{p}=$ 0.337). Further examined complications can be found in table 2 .

The surgical result was worse in underweight patients, showing more often aboral $(\mathrm{p}<0.001)$ and radial $(\mathrm{p}=0.006)$ tumor-positive resection margins than in normal-weight patients. The radial margins of overweight and obese patients were less often positive. The oral $(\mathrm{p}=0.764)$ as well as resection margins at adjacent organs $(\mathrm{p}=$ $0.142)$ and distant metastasis $(p=0.722)$ showed no significant association to BMI. The quality of total mesorectal excision was also comparable among the groups. Diagnosed coning $(p=0.132)$ as well as the gradation according to the Mercury classification did not differ significantly $(\mathrm{p}=0.075)$ (table 3$)$. 


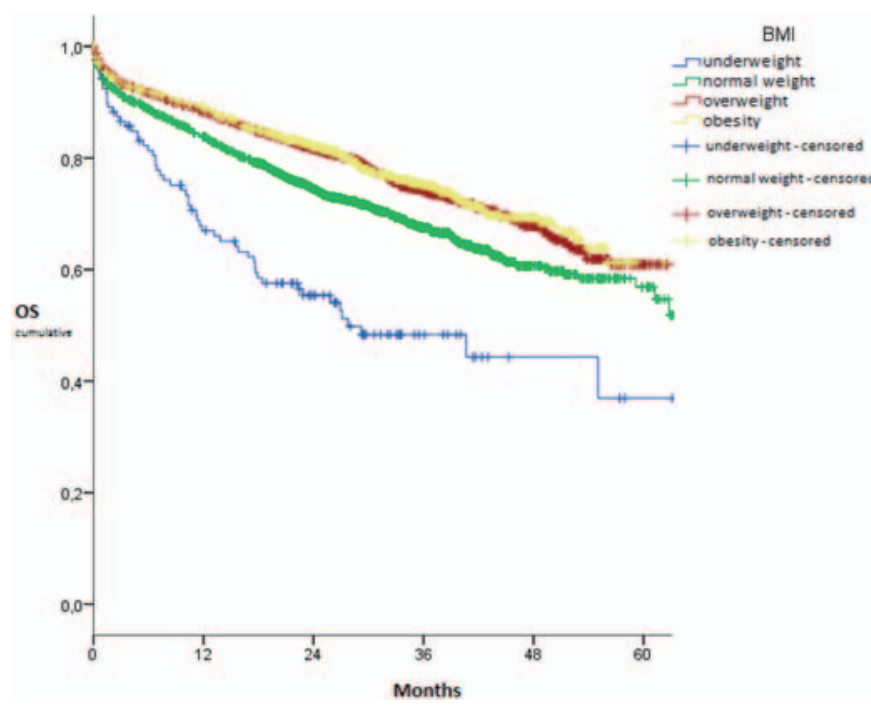

Fig. 1. 5-year overall survival depending on $\mathrm{BMI}\left(\mathrm{kg} / \mathrm{m}^{2}\right)$ in rectal cancer surgery.

In total, $93.9 \%$ of all patients were regularly discharged from the hospital. Underweight ones (86.8\%) were less likely discharged ( $\mathrm{p}<$ $0.001)$ but were more often transferred to another clinic or hospital $(8.5 \%$; $<<0.001)$ than other patients who were discharged in $93.4-$ $94.6 \%$ and transferred in $2.7-3.1 \%$ of cases. The mean in-hospital mortality was $3.1 \%$ and did not depend on the patient's BMI ( $\mathrm{p}=$ 0.176). Adjuvant therapy was planned for $43.0 \%$ of the patients, without BMI-dependent differences concerning radiochemotherapy $(\mathrm{p}=0.070)$ or chemotherapy $(\mathrm{p}=0.100)$. Palliative chemotherapy $(\mathrm{p}$ $<0.001)$ or radiation $(\mathrm{p}=0.003)$ were more often planned for underweight and less often scheduled for overweight and obese patients compared to normal-weight ones (table 4). The impact of the BMI onto the 5-year OS was analyzed in 5,995 patients. Taken together, 1,608 events were recorded and 4,387 patients were censored. Underweight patients showed an OS of $36.9 \%$ after 5 years, which was significantly lower than in normal-weight ones with $56.9 \%$ ( $\mathrm{p}<$ $0.001)$. Overweight $(60.9 \%)$ and obese $(61.3 \%)$ patients had a significantly longer 5-year OS than normal-weight patients $(\mathrm{p}<0.001$ each) (fig. 1). The 5-year DFS was analyzed in 4,441 patients, with 1,128 recorded events and 3,313 censored patients. Showing a DFS of $49.1 \%$ after 5 years, underweight patients had a DFS comparable to normal-weight cases, i.e. $54.2 \%$ ( $\mathrm{p}=0.168$ ). Overweight subjects, showing $63.1 \%$ after 5 years, had a significantly longer DFS than in case of normal weight $(\mathrm{p}=0.001)$. Although obese patients showed a 5 -year DFS of merely $51.5 \%$, concerning the whole curve their DFS was still significantly better than in subjects with normal weight $(\mathrm{p}=$ 0.027 ) (fig. 2). Local recurrence was observed in 114 events, leading to 4,283 censored patients and 4,397 patients in total. The local recurrence rate after 5 years was $6.1 \%$ in underweight, $4.3 \%$ in normalweight, $5.3 \%$ in overweight and $7.5 \%$ in obese patients. There were no significant differences ( $\mathrm{p}>0.05$ each).

In total, 6,530 patients were included in the analysis for morbidity and in-hospital mortality. A number of 1,258 events was registered for 5-year OS, leading to 3,474 censored patients, whereas

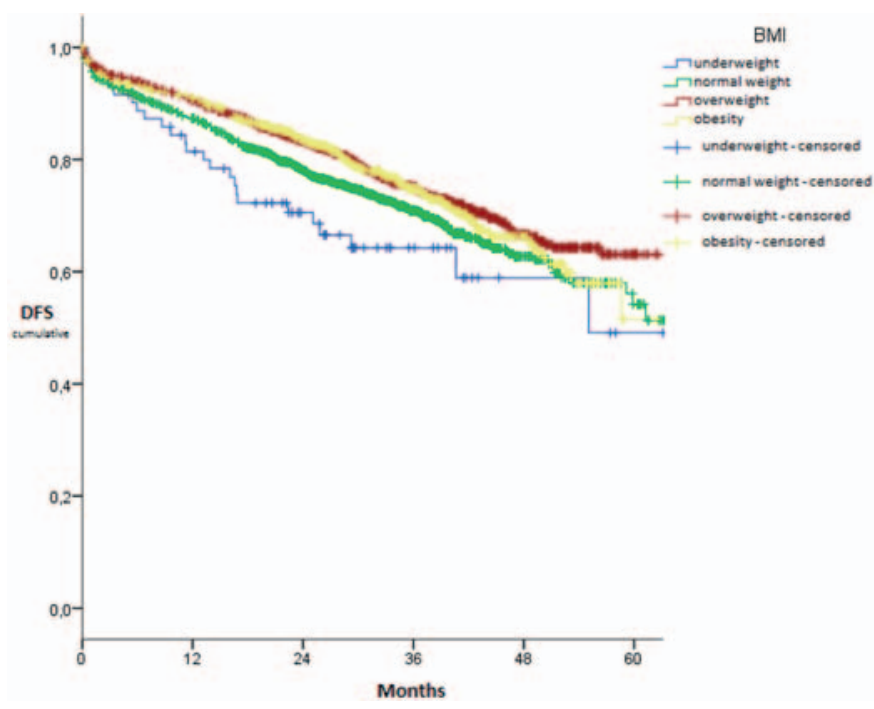

Fig. 2. 5-year disease-free survival depending on $\mathrm{BMI}\left(\mathrm{kg} / \mathrm{m}^{2}\right)$ in rectal cancer surgery.

1,001 events were recorded concerning 5-year DFS with 2,960 censored patients. In accordance with univariate results, obesity was an independent risk factor for postoperative complications with an OR of 1.31 (95\% CI: 1.12-1.55) compared to normal weight. Remarkably, preoperative bowel preparation reduced the risk $(\mathrm{OR}=0.85$; 95\% CI: 0.73-0.99). The BMI was not an independent risk factor for in-hospital mortality. Perioperative (OR $=1.85$; 95\% CI: 1.19-2.87) and especially postoperative complications $(\mathrm{OR}=128.77$; $95 \% \mathrm{CI}$ : 31.73-522.21) increased the risk for in-hospital mortality. Administration of a neoadjuvant therapy reduced this risk ( $\mathrm{OR}=0.59 ; 95 \%$ CI: 0.40-0.88). Multivariate analysis revealed that underweight did not increase the HR for 5 -year OS (HR $=1.02$; 95\% CI: 0.71-1.48) whereas overweight ( $\mathrm{HR}=0.84$; 95\% CI: $0.74-0.95)$ and obesity $(\mathrm{HR}=0.78$; 95\% CI: 0.66-0.91) reduced the HR. Preoperative bowel preparation reduced the risk as well ( $\mathrm{HR}=0.86$; 95\% CI: 0.75-0.98) in a similar manner as the creation of an anastomosis compared to no anastomosis ( $\mathrm{HR}=0.77$; 95\% CI: 0.69-0.87). General (HR = 2.42; 95\% CI: 2.14-2.73) and surgery-related postoperative complications (HR $=1.20$; 95\% CI: 1.07-1.35) worsened the 5-year OS independently. The 5-year DFS was not independently influenced by the BMI. Creation of an anastomosis was associated with a $\mathrm{HR}$ of 0.75 (95\% CI: $0.66-0.86)$ and was the only item that improved the HR for 5-year DFS. General (HR = 2.38; 95\% CI: 2.07-2.72) and surgery-related morbidity $(\mathrm{HR}=1.25 ; 95 \% \mathrm{CI}: 1.09-1.43)$ as well as resections of multiple organs ( $\mathrm{HR}=1.27$; 95\% CI: $1.05-1.54$ ) worsened the 5-year DFS. All other results of the performed multivariate analysis are shown in tables 5-7.

\section{Discussion}

Referring to the Robert Koch-Institute (Berlin, Germany), a total number of 79,524 rectal cancer cases (31,359 women, 48,165 men) occurred annually between 2008 and 2011 [11]. Thus, this 
Table 5. Results of logistic regression for postoperative morbidity in rectal cancer surgery

\begin{tabular}{|c|c|c|c|}
\hline Parameter & Odds ratio & $\begin{array}{l}95 \% \text { confidence } \\
\text { interval }\end{array}$ & p-value \\
\hline \multicolumn{4}{|l|}{ Reference: normal weight } \\
\hline Underweight & 1.164 & $0.754-1.796$ & 0.492 \\
\hline Overweight & 1.044 & $0.915-1.191$ & 0.527 \\
\hline Obesity & 1.312 & $1.115-1.545$ & 0.001 \\
\hline \multicolumn{4}{|l|}{ Reference: tumor height $12-16 \mathrm{~cm}$ from anal verge } \\
\hline Tumor height from anal verge $0-3.9 \mathrm{~cm}$ & 1.294 & $1.016-1.647$ & 0.037 \\
\hline Tumor height from anal verge $4-7.9 \mathrm{~cm}$ & 1.325 & $1.113-1.579$ & 0.002 \\
\hline Tumor height from anal verge $8-11.9 \mathrm{~cm}$ & 1.340 & $1.144-1.569$ & $<0.001$ \\
\hline Familial adenomatous polyposis, yes & 2.498 & $0.864-7.221$ & 0.091 \\
\hline \multicolumn{4}{|l|}{ Reference: ASA 1} \\
\hline ASA 2 & 1.082 & $0.850-1.377$ & 0.522 \\
\hline ASA 3 & 1.276 & $0.996-1.634$ & 0.054 \\
\hline ASA 4 & 2.893 & $1.799-4.652$ & $<0.001$ \\
\hline Distant metastasis, yes & 1.174 & $1.001-1.377$ & 0.048 \\
\hline Preoperative bowel preparation, yes & 0.850 & $0.728-0.991$ & 0.038 \\
\hline Preoperative endorectal ultrasonography, yes & 0.895 & $0.786-1.018$ & 0.090 \\
\hline \multicolumn{4}{|l|}{ Reference: no antibiotics given } \\
\hline Antibiotic prophylaxis & 1.652 & $1.090-2.503$ & 0.018 \\
\hline Antibiotic therapy & 1.907 & $1.247-2.914$ & 0.003 \\
\hline Creation of an anastomosis, yes & 0.848 & $0.719-1.000$ & 0.050 \\
\hline Perioperative complications, yes & 1.976 & $1.542-2.533$ & $<0.001$ \\
\hline Duration of surgery, increasing & 1.001 & $1.000-1.002$ & 0.068 \\
\hline Duration of hospital stay, increasing & 1.125 & $1.116-1.134$ & $<0.001$ \\
\hline \multicolumn{4}{|l|}{ Reference: 12-18 lymph nodes examined } \\
\hline$<12$ lymph nodes examined & 1.243 & $1.042-1.482$ & 0.015 \\
\hline$>18$ lymph nodes examined & 1.038 & $0.914-1.178$ & 0.567 \\
\hline
\end{tabular}

study includes one eighth of all rectal cancer cases that occurred in Germany during this time period with an adequate sex ratio. Due to the large amount of acquired patient data and the consecutive follow-up, a detailed profile of every patient was created. In combination with multivariate analysis considering the mentioned endpoints, further influencing factors were identified and used to assess the impact of BMI on the outcome measures. Data obtained from hospitals of all levels of clinical care were included. In conclusion, the results can be considered as representative for the oncosurgical care of rectal cancer in Germany.

There are a few limitations to the study, e.g. by means of the retrospective analysis of data that, however, was obtained from the participating hospitals and documented in a prospective setting. In addition, due to the study design (data from daily clinical work, multicenter setting), it is not possible to foreclose incorrect and double reports on single items. Validity criteria implemented in the database were used to minimize this bias during data registration.

\section{Impact of Obesity}

Less advanced tumor stages in the overweight and obese patients compared to normal-weight ones may be caused by a catabolic metabolism in advanced cancer patients. Thus, primarily obese or overweight patients could be classified as 'just' overweight or normal weight at the time point of hospital admission. This hy- pothesis is supported by national data on obesity in the relevant age groups of 60-69 and 70-79 years. These show prevalence rates of at least $30 \%$, which is a 1.5 -fold higher rate than the $19.4 \%$ in our patient cohort [12]. The lower age of obese patients at admission may also be an indicator for this hypothesis. In our study, the physical status (ASA) was worse in those patients, which also showed more comorbidities, especially cardiovascular risk factors and diabetes mellitus (data not shown). These findings are not surprising and have been widely described in the literature [2, 13-15].

In total, $42.9 \%$ of obese patients developed postoperative complications, which was a significantly higher percentage than in normal-weight patients. In particular, studies with large sample sizes show concordant results $[3,5,15]$ despite the fact that there is literature reporting no(t) significantly increased morbidity rates [14, 16]. Increased morbidity in obese patients was mostly due to higher rates of wound infections. The association of obesity and infectious complications has been consistently shown in the literature $[2,3,13-15,17]$. Options to reduce this increase in morbidity after general surgery and particularly rectal cancer resections include a laparoscopic approach or high inspired oxygen concentrations perioperatively $[18,19]$. The fact that the least severe complications increased morbidity rates in obese patients is logic but these did not cause increased in-hospital mortality. For general surgery, Mullen et al. [17] presented results of an 'obesity paradox' 
Table 6. Results of logistic regression for in-hospital death in rectal cancer surgery

\begin{tabular}{lrll}
\hline Parameter & Odds ratio & $95 \%$ confidence interval & p-value \\
\hline Reference: Age $<65$ years & & & \\
$\quad$ Age 65-74 years & 2.084 & $1.164-3.730$ & 0.013 \\
$\quad$ Age $\geq 75$ years & 4.014 & $2.285-7.051$ & $<0.001$ \\
Second malignancy, yes & 1.745 & $1.189-2.560$ & 0.004 \\
\hline Reference: ASA 1 & & & \\
ASA 2 & 2.778 & $0.374-20.641$ & 0.318 \\
ASA 3 & 6.751 & $0.917-49.718$ & 0.061 \\
ASA 4 & 33.447 & $4.388-254.926$ & 0.001 \\
Neoadjuvant therapy, yes & 0.592 & $0.399-0.877$ & 0.009 \\
$\quad$ Perioperative complications, yes & 1.850 & $1.192-2.871$ & 0.006 \\
$\quad$ Postoperative morbidity, yes & 128.773 & $31.734-522.210$ & $<0.001$ \\
Length of hospital stay, increasing & 0.991 & $0.982-1.001$ & 0.090 \\
\hline Reference: R0 resection & & & \\
R1 resection status & 0.714 & $0.312-1.636$ & 0.426 \\
R2 resection status & 1.666 & $1.140-2.435$ & 0.008 \\
\hline Reference: 12-18 lymph nodes examined & & & 0.435 \\
$\quad<12$ lymph nodes examined & 0.818 & $0.495-1.353$ & 0.001 \\
$\quad>18$ lymph nodes examined & 0.542 & $0.383-0.767$ & \\
\hline
\end{tabular}

with decreased mortality rates for obese patients. It appears that this is not applicable to colorectal resections as our results and those of other authors show $[5,7,14,20]$. On the contrary, overweight and obese patients showed an independently increased OS. The 'obesity paradox' for long-term outcome after general surgery was described by Tjeertes et al. [2]. The fact that these patients had less advanced tumor stages than normal-weight subjects, as was also found in the study presented here, might have had an influence. Ballian et al. [7] encountered comparable tumor stages throughout their patients and did not find evidence for a better OS or DFS after patients had undergone proctectomy. However, the mean follow-up time period was relatively short (i.e. 23 months). You et al. [8] did not find a better outcome for those patients either but they only included anterior resections with curative intent.

\section{Impact of Underweight}

The catabolism theory for obese patients with less advanced tumor stages, as mentioned above, can be used for underweight cases in the opposite manner. In our analysis, $2.1 \%$ of all patients were underweight, compared to national population data of 0.1 $0.2 \%$ in men and $0.2-1.9 \%$ in women depending on the age group of 60-69 or 70-79 years, respectively [12]. Preoperative weight loss is more common in underweight patients than in others $[13,17]$. Prospective randomized controlled trials, in which parameters of malnutrition are also analyzed, are necessary for further investigation of this topic. Similar to obese patients, underweight subjects showed a worse physical status (according to ASA scoring) preoperatively and a comparable morbidity postoperatively. Thus, advanced tumor stages have to be kept in mind. Yasunaga et al. [3] reported that even after adjustment for tumor stages, underweight patients with colorectal and gastric cancer undergoing resection developed more complications than normal-weight patients. Multiple studies indicate that increased rates of preoperative risk fac- tors are the reason for higher morbidity but not underweight itself $[2,13,17,21]$. This is in accordance with the results of our multivariate analysis. In contrast to many other studies, our results did not show an increased mortality for underweight patients $[3,5,13$, $15,17]$. Adequate selection of patients for surgery and sufficient management of complications in case of their occurrence are possible reasons for this specific result. There is some evidence that pre- and perioperative nutritional support can be considered an option to substantially improve the problematic short-term outcome of underweight individuals. Carried out for a certain time period after surgery, this measure was able to improve at least morbidity [22-24].

The long-term outcome was also worse in underweight patients. These patients had a reduced physical status and more advanced tumor stages preoperatively as well as a worse early postoperative result. Furthermore, in multivariate analysis, underweight was not identified as an independent factor that increases the HR for OS and DFS. In conclusion, the associated risk factors that were identified for worsening OS and DFS but not underweight itself altered the long-term (oncological) outcome as well as the early postoperative results after rectal cancer surgery.

\section{Further Influencing Factors}

More advanced tumor stages, especially with lymph node invasion or distant metastasis, were factors that negatively influence the short- and long-term outcome. Since these factors cannot be directly influenced, they should not be discussed at this point. Aspects of clinical care and surgical quality should rather be considered.

Neoadjuvant treatment might decrease in-hospital mortality. However, if a patient has severe comorbidities and risk factors such as cardiovascular risks, it is likely that this particular patient does not undergo radiation or chemotherapy prior to surgery. Holubar 
Table 7. Cox regression for 5-year overall and disease-free survival in rectal cancer surgery

\begin{tabular}{|c|c|c|c|c|c|c|}
\hline \multirow[t]{2}{*}{ Parameter } & \multicolumn{3}{|c|}{ Overall survival } & \multicolumn{3}{|c|}{ Disease-free survival } \\
\hline & HR & $95 \%$ CI & $\mathrm{p}$-value & HR & $95 \%$ CI & p-value \\
\hline \multicolumn{7}{|l|}{ Reference: age $<65$ years } \\
\hline Age 65-74 years & 1.409 & $1.203-1.651$ & $<0.001$ & 1.312 & $1.104-1.561$ & 0.002 \\
\hline Age $\geq 75$ years & 2.166 & $1.845-2.542$ & $<0.001$ & 2.082 & $1.747-2.481$ & $<0.001$ \\
\hline \multicolumn{7}{|l|}{ Reference: normal weight } \\
\hline Underweight & 1.023 & $0.708-1.477$ & 0.905 & - & - & - \\
\hline Overweight & 0.837 & $0.737-0.951$ & 0.006 & - & - & - \\
\hline Obesity & 0.777 & $0.661-0.912$ & 0.002 & - & - & - \\
\hline Second malignancy, yes & 1.245 & $1.060-1.461$ & 0.008 & 1.342 & $1.120-1.609$ & 0.001 \\
\hline \multicolumn{7}{|l|}{ Reference: no preoperative histological finding } \\
\hline Histology without carcinoma proof & 1.591 & $0.969-2.611$ & 0.066 & - & - & - \\
\hline Histological diagnosis of a carcinoma & 1.019 & $0.744-1.395$ & 0.907 & - & - & - \\
\hline Intraepithelial high-grade neoplasia & 0.630 & $0.320-1.238$ & 0.180 & - & - & - \\
\hline Distant metastasis, yes & 1.694 & $1.314-2.185$ & $<0.001$ & - & - & - \\
\hline Preoperative risk factors & 1.210 & $0.976-1.501$ & 0.083 & - & - & - \\
\hline \multicolumn{7}{|l|}{ Reference: ASA 1} \\
\hline ASA 2 & 1.137 & $0.810-1.596$ & 0.458 & 1.329 & $0.962-1.838$ & 0.085 \\
\hline ASA 3 & 1.783 & $1.242-2.560$ & 0.002 & 1.925 & $1.384-2.679$ & $<0.001$ \\
\hline ASA 4 & 3.623 & $2.356-5.570$ & $<0.001$ & 3.944 & $2.599-5.987$ & $<0.001$ \\
\hline Preoperative bowel preparation, yes & 0.856 & $0.746-0.983$ & 0.028 & - & - & - \\
\hline Creation of an anastomosis, yes & 0.773 & $0.687-0.871$ & $<0.001$ & 0.753 & $0.659-0.860$ & $<0.001$ \\
\hline Resection of multiple organs, yes & - & - & - & 1.273 & $1.053-1.539$ & 0.013 \\
\hline General postoperative complication, yes & 2.417 & $2.140-2.730$ & $<0.001$ & 2.375 & $2.071-2.724$ & $<0.001$ \\
\hline Surgery-related postoperative complications, yes & 1.203 & $1.069-1.353$ & 0.002 & 1.251 & $1.094-1.431$ & 0.001 \\
\hline \multicolumn{7}{|l|}{ Reference: $12-18$ lymph nodes examined } \\
\hline$<12$ lymph nodes examined & 0.882 & $0.736-1.058$ & 0.176 & - & - & - \\
\hline$>18$ lymph nodes examined & 0.790 & $0.698-0.893$ & $<0.001$ & - & - & - \\
\hline \multicolumn{7}{|l|}{ Reference: grading G1 } \\
\hline G2 & 0.887 & $0.619-1.270$ & 0.512 & 0.806 & $0.562-1.156$ & 0.241 \\
\hline G3 & 1.089 & $0.752-1.576$ & 0.653 & 1.026 & $0.700-1.504$ & 0.895 \\
\hline G4 & 3.695 & $1.440-9.479$ & 0.007 & 3.557 & $0.478-26.456$ & 0.215 \\
\hline GX & 1.037 & $0.638-1.685$ & 0.883 & 0.880 & $0.531-1.456$ & 0.618 \\
\hline No information about grading & 1.232 & $0.775-1.959$ & 0.377 & 1.330 & $0.842-2.099$ & 0.222 \\
\hline \multicolumn{7}{|l|}{ Reference: pT 1} \\
\hline pT 2 & 1.307 & $0.969-1.763$ & 0.080 & 1.412 & $1.076-1.853$ & 0.013 \\
\hline pT 3 & 1.866 & $1.403-2.482$ & $<0.001$ & 2.007 & $1.546-2.604$ & $<0.001$ \\
\hline pT 4 & 2.430 & $1.774-3.328$ & $<0.001$ & 2.463 & $1.757-3.453$ & $<0.001$ \\
\hline \multicolumn{7}{|l|}{ Reference: $\mathrm{pN} 0$} \\
\hline pN1 & 1.272 & $1.083-1.493$ & 0.003 & 1.605 & $1.380-1.867$ & $<0.001$ \\
\hline $\mathrm{pN} 2$ & 1.692 & $1.412-2.027$ & $<0.001$ & 2.222 & $1.867-2.644$ & $<0.001$ \\
\hline \multicolumn{7}{|l|}{ Reference: $\mathrm{R} 0$ resection status } \\
\hline $\mathrm{R} 1$ & 1.368 & $1.055-1.774$ & 0.018 & - & - & - \\
\hline $\mathrm{R} 2$ & 1.755 & $1.343-2.294$ & $<0.001$ & - & - & - \\
\hline $\mathrm{RX}$ & 1.525 & $0.780-2.982$ & 0.217 & - & - & - \\
\hline \multicolumn{7}{|l|}{ Reference: pL 0} \\
\hline pL 1 & 1.188 & $1.023-1.381$ & 0.024 & - & - & - \\
\hline pL 2 & 1.506 & $0.998-2.272$ & 0.051 & - & - & - \\
\hline Not examined & 0.876 & $0.585-1.313$ & 0.523 & - & - & - \\
\hline \multicolumn{7}{|l|}{ Reference: $\mathrm{pV} 0$} \\
\hline $\mathrm{pV} 1$ & 1.080 & $0.931-1.252$ & 0.308 & - & - & - \\
\hline $\mathrm{pV} 2$ & 1.964 & $1.139-3.389$ & 0.015 & - & - & - \\
\hline Not examined & 1.284 & $0.889-1.857$ & 0.183 & - & - & - \\
\hline
\end{tabular}


et al. [25] showed matching results for this theory. Schiffmann et al. [26] could not demonstrate a significant benefit of neoadjuvant treatment concerning mortality. ASA classification, age, and cardiovascular risk were comparable among their patients [26]. Preoperative bowel preparation is also a matter of ongoing discussion. In terms of postoperative complication rates, and in accordance with the results of Bretagnol et al. [27] obtained in their randomized trial, the presented study showed favorable results for performing this procedure. Concerning clinical decision-making, the influence of higher age and more critical ASA score must be considered. Both factors independently increased in-hospital mortality. Other large studies support this finding $[10,20]$. Additionally, higher age independently reduced the 5-year OS and 5-year DFS, supporting former results of the Eindhoven Cancer registry $[28,29]$. Those influences should be kept in mind when it comes to patient selection. Nevertheless, surgery remains the key in the treatment of rectal cancer. Perioperatively, a resection that is not free of residual tumor (R1 and R2 status) was associated with an increased in-hospital mortality and worse OS; thus, surgeons are obliged to make an effort in order to achieve an $\mathrm{R} 0$ resection. This aspect was also described by Radwan et al. [30]. Furthermore, the results of our study emphasize the need of a developed and sufficient complication prevention regimen. Perioperative complications triggered postoperative complications which themselves increased the in-hospital death rate and impaired the long-term (oncological) outcome (represented by OS and DFS). Aspects of increased morbidity due to longer hospital stay or harvest/examination of less than twelve lymph nodes have to be considered, though. If there were complications leading to a longer hospital stay, this was most likely caused by treatment measures. However, it cannot be ruled out that nosocomial infections possibly occurring during an extended hospital stay might have specifically increased the morbidity. A limited amount of lymph nodes might have been caused by difficulties during resections or other aspects that made it impossible to harvest or examine the number of lymph nodes as required by national guidelines.

\section{Key Messages}

Obesity increases postoperative morbidity but does not have an impact onto in-hospital mortality. In contrast, similar to overweight, it is associated with a longer OS which can be considered a long-term 'obesity paradox'. An obesity paradox concerning inhospital mortality is not applicable to the study population, though. In addition, underweight is also associated with increased morbidity but not mortality. A shorter OS and DFS after 5 years is most likely due to worse physical status and more advanced tumor diseases preoperatively.

\section{What Is Already Known about this Project?}

Obesity worsens postoperative morbidity after rectal cancer resection; however, a negative impact onto in-hospital mortality is unlikely. Some authors refer to an 'obesity paradox' in long-term outcomes, describing improved survival rates for overweight and obese patients. However, the literature is inconsistent about this subject.

The study design of a prospective multicenter observational study to reflect daily surgical practice as a contribution to research on clinical care can be considered an established and sufficient tool to characterize early postoperative and long-term oncosurgical outcome in cancer surgery in a consecutive patient cohort over a well-defined time period, which was the main goal in the presented comparable studies.

\section{What Does this Study Add?}

This study investigated the impact of various ranges of BMI in rectal cancer patients (e.g. underweight in the same way as the impact of obesity) on the tumor outcome. All tumor stages of rectal cancer and all kinds of rectal cancer surgery were included, and WHO definitions for various patient groups were used. Furthermore, the current situation of clinical care in Germany is characterized by employing a representative registry of patients whose data were obtained from a great number of participating surgical departments of each level of care.

The impact of underweight onto morbidity, mortality, and survival in general surgery and particularly rectal cancer resections is rarely investigated. Furthermore, several definitions are used to classify underweight, thus leading to less generalization of study findings. A negative impact on the mentioned parameters is likely.

In addition, the study revealed that underweight patients had a worse early and long-term outcome after rectal cancer surgery than normal-weight patients. Overweight and obesity were related to a significantly better long-term survival.

\section{Disclosure Statement}

The authors declare no conflict of interest.

\section{References}

1 Haidar YM, Cosman BC: Obesity epidemiology. Clin Colon Rectal Surg 2011;24:205-210.

2 Tjeertes EKM, Hoeks SE, Beks SBJ, Valentijn TM Hoofwijk AGM, Stolker RJ: Obesity - a risk factor for postoperative complications in general surgery? BMC Anesthesiol 2015;15:112.

3 Yasunaga H, Horiguchi H, Matsuda S, Fushimi K, Hashimoto H, Ayanian JZ: Body mass index and outcomes following gastrointestinal cancer surgery in Japan. Br J Surg 2013;100:1335-1343.
4 Siegel RL, Miller KD, Jemal A: Cancer Statistics, 2017. CA Cancer J Clin 2017;67:7-30.

5 Hede P, Sörensson MÅ, Polleryd P, Persson K, Hallgren $\mathrm{T}$ : Influence of BMI on short-term surgical outcome after colorectal cancer surgery: a study based on the Swedish national quality registry. Int J Colorectal Dis 2015;30:1201-1207.
6 Zhou Y, Wu L, Li X, Wu X, Li B: Outcome of laparoscopic colorectal surgery in obese and nonobese patients: a meta-analysis. Surg Endosc 2012;26:783-789.

7 Ballian N, Yamane B, Leverson G, Harms B, Heise CP, Foley EF, Kennedy GD: Body mass index does not affect postoperative morbidity and oncologic outcomes of total mesorectal excision for rectal adenocarcinoma. Ann Surg Oncol 2010;17:1606-1613. 
8 You J-F, Tang R, Changchien CR, Chen J-S, You Y-T, Chiang J-M, Yeh C-Y, Hsieh P-S, Tsai W-S, Fan C-W, Hung H-Y: Effect of body mass index on the outcome of patients with rectal cancer receiving curative anterior resection: disparity between the upper and lower rectum. Ann Surg 2009;249:783-787.

9 World Health Organization: Obesity: Preventing and Managing the Global Epidemic Report of a WHO Consultation. WHO Technical Report Series, vol 894. Geneva, 2000.

10 Marusch F, Koch A, Schmidt U, Steinert R, Ueberrueck T, Bittner R, Berg E, Engemann R, Gellert K, Arbogast R, Korner T, Köckerling F, Gastinger I, Lippert $\mathrm{H}$ : The impact of the risk factor 'age' on the early postoperative results of surgery for colorectal carcinoma and its significance for perioperative management. World J Surg 2005;29:1013-1021; discussion 1021-1022.

11 Robert Koch-Institute: The German Centre for Cancer Registry Data (ZfKD).www.krebsdaten.de/Krebs/EN/ Database/databasequery_step1_node.html (accessed November 7, 2016)

12 Mensink GBM, Schienkiewitz A, Haftenberger M, Lampert T, Ziese T, Scheidt-Nave C: Overweight and obesity in Germany: results of the German Health Interview and Examination Survey for Adults (DEGS1). Bundesgesundheitsblatt Gesundheitsforschung Gesundheitsschutz 2013;56:786-794.

13 Smith RK, Broach RB, Hedrick TL, Mahmoud NN Paulson EC: Impact of BMI on postoperative outcomes in patients undergoing proctectomy for rectal cancer: a national surgical quality improvement program analysis. Dis Colon Rectum 2014;57:687-693.

14 Bokey L, Chapuis PH, Dent OF: Impact of obesity on complications after resection for rectal cancer. Colorectal Dis 2014;16:896-906.
15 Hrabe JE, Sherman SK, Charlton ME, Cromwell JW, Byrn JC: Effect of BMI on outcomes in proctectomy. Dis Colon Rectum 2014;57:608-615.

16 Aytac E, Lavery IC, Kalady MF, Kiran RP: Impact of obesity on operation performed, complications, and long-term outcomes in terms of restoration of intestinal continuity for patients with mid and low rectal cancer. Dis Colon Rectum 2013;56:689-697.

17 Mullen JT, Moorman DW, Davenport DL: The obesity paradox: body mass index and outcomes in patients undergoing nonbariatric general surgery. Ann Surg 2009;250:166-172.

18 Kiran RP, El-Gazzaz GH, Vogel JD, Remzi FH: Laparoscopic approach significantly reduces surgical site infections after colorectal surgery: data from national surgical quality improvement program. J Am Coll Surg 2010;211:232-238.

19 Schietroma M, Cecilia EM, Sista F, Carlei F, Pessia B, Amicucci G: High-concentration supplemental perioperative oxygen and surgical site infection following elective colorectal surgery for rectal cancer: a prospective, randomized, double-blind, controlled, single-site trial. Am J Surg 2014;208:719-726.

20 Masoomi H, Kang CY, Chen A, Mills S, Dolich MO, Carmichael JC, Stamos MJ: Predictive factors of inhospital mortality in colon and rectal surgery. J Am Coll Surg 2012;215:255-261.

21 Kim J-M, Park J-H, Jeong S-H, Lee Y-J, Ju Y-T, Jeong C-Y, Jung E-J, Hong S-C, Choi S-K, Ha W-S: Relationship between low body mass index and morbidity after gastrectomy for gastric cancer. Ann Surg Treat Res 2016;90:207-212.

22 Wu G-H: Perioperative artificial nutrition in malnourished gastrointestinal cancer patients. World J Gastroenterol 2006;12:2441-2444.
23 Jie B, Jiang Z-M, Nolan MT, Zhu S-N, Yu K, Kondrup $\mathrm{J}$ : Impact of preoperative nutritional support on clinical outcome in abdominal surgical patients at nutritional risk. Nutrition 2012;28:1022-1027.

24 Bozzetti F, Gavazzi C, Miceli R, Rossi N, Mariani L, Cozzaglio L, Bonfanti G, Piacenza S: Perioperative total parenteral nutrition in malnourished, gastrointestinal cancer patients: a randomized, clinical trial. JPEN J Parenter Enteral Nutr 2000;24:7-14.

25 Holubar SD, Brickman RK, Greaves SW, Ivatury SJ: Neoadjuvant radiotherapy: a risk factor for short-term wound complications after radical resection for rectal cancer? J Am Coll Surg 2016;223:291-298.

26 Schiffmann L, Wedermann N, Gock M, Prall F, Klautke G, Fietkau R, Rau B, Klar E: Intensified neoadjuvant radiochemotherapy for rectal cancer enhances surgical complications. BMC Surg 2013;13:43.

27 Bretagnol F, Alves A, Ricci A, Valleur P, Panis Y: Rectal cancer surgery without mechanical bowel preparation. Br J Surg 2007;94:1266-1271.

28 Lemmens VEPP, Janssen-Heijnen MLG, Verheij CDGW, Houterman S, Repelaer van Driel OJ, Coebergh JWW: Co-morbidity leads to altered treatment and worse survival of elderly patients with colorectal cancer. Br J Surg 2005;92:615-623.

29 Janssen-Heijnen MLG, Maas, Huub AAM, Houterman S, Lemmens, Valery EPP, Rutten HJT, Coebergh JWW: Comorbidity in older surgical cancer patients: influence on patient care and outcome. Eur J Cancer 2007; 43:2179-2193.

30 Radwan RW, Jones HG, Rawat N, Davies M, Evans MD, Harris DA, Beynon J: Determinants of survival following pelvic exenteration for primary rectal cancer. Br J Surg 2015;102:1278-1284. 